\title{
SAMBA E CARNAVAL À PAULI STA UMA FOLIA EM SANTANA DO PARNAÍBA
}

Simone Toji

Por meio da apresentação do caso do carnaval realizado na cidade paulista de Santana do Parnaíba, o artigo visa problematizar o senso comum de que o estado de São Paulo não possui samba nem carnaval de importância ou que o carnaval e o samba existentes sejam imitação de modelos como o carioca ou o nordestino. Ao mesmo tempo, identifica o samba de bumbo como referência de manifestação particular no mundo do samba em São Paulo e sugere que o carnaval realizado em Santana do Parnaíba por meio do samba de bumbo possui elementos da carnavalização bakhtiniana.

SAMBA, CARNAVAL, SÃO PAULO, SAMBA DE BUMBO, SANTANA DO PARNAÍBA.

TOJI, Simone. Samba e carnaval à paulista: uma folia em Santana do Parnaíba. Textos escolhidos de cultura e arte populares, Rio de Janeiro, v.6, n.1, p. 159172, 2009. 


\section{UM POUQUINHO SOBRE SAMBA E CARNAVAL EM SÃO PAULO}

Quando alguém pensa em carnaval no Brasil, logo pipocam imagens de folias cariocas, nordestinas, interioranas. Quando alguém pensa em samba no Brasil, logo brotam as referências do Rio de Janeiro e do Recôncavo Baiano. Raramente alguém irá sugerir São Paulo como território de qualquer representatividade das manifestações do carnaval ou do samba. Desde que Vinícius de Moraes vaticinou que "São Paulo é o túmulo do samba", o senso comum nacional mais recente consentiu e consolidou duas imagens muito influentes: 1) São Paulo não possui samba nem carnaval de importância; 2) o carnaval e o samba que existem em São Paulo são imitação de modelos de outros lugares do Brasil, principalmente do Rio de Janeiro.

Sem desconsiderar a dinâmica atual que toma conta da apresentação das escolas de samba paulistanas, na qual os padrões cariocas dos desfiles competitivos são cada vez mais apropriados para a realização do evento na capital paulistana, estudos acadêmicos e movimentos culturais locais têm se dedicado a desvelar histórias e expressões muito particulares do que seja o samba e o carnaval em São Paulo, contribuindo para iluminar áreas antes ignoradas ou obscuras sobre o assunto.

Os trabalhos de Simson (2007), consolidados por meio do Centro de Memória da Universidade Estadual de Campinas (UNICAMP) e da formação do Núcleo de Samba Cupinzeiro na região da cidade de Campinas; as atividades do Centro de Documentação e Memória do Samba Paulista, ligado à União das Escolas de Samba Paulistanas; ou mesmo o fenômeno do Samba da Vela - estes dois últimos situados na capital do estado - são todos exemplos das citadas iniciativas.

Cada vez mais esses estudos e produções culturais encontram na pesquisa histórica sobre a articulação samba e carnaval, principalmente relacionada à região metropolitana, argumentos corroboradores para reivindicar certa "autenticidade" no mundo do samba e para expressar o samba e o carnaval realizados em território paulista enquanto produtos "originais", merecedores de atenção diferenciada. De que maneira isso se dá?

Formas de expressão do samba em São Paulo chamados de samba antigo, samba caipira, samba de bumbo, samba de terreiro, samba de umbigada, samba lenço, samba sertanejo, o batuque são identificados por estudos e pesquisas enquanto elementos muito particulares do universo paulista. Ao mesmo tempo, muitos depoimentos de componentes das escolas de samba paulistanas rememoram a participação dos seus fundadores em tais formas de expressão "ancestrais". Desse modo, por meio do agenciamento da memória, a possibilidade de se pensar a origem das atuais agremiações de samba urbanas a partir dessas formas "tradicionais" permite aos sambistas, sambadores e sambadeiras de São Paulo se intitularem enquanto expressões originais e diferenciadas do que seja o samba ou o carnaval no Brasil.

A principal manifestação de referência para a memória da formação das escolas de samba paulistanas é o samba de bumbo ou de roda de Pirapora do Bom Jesus ${ }^{1}$. Tal expressão está vinculada à devoção de romeiros que, nas primeiras semanas do mês de 
agosto, se dirigem à cidade de Pirapora do Bom Jesus para pagar suas promessas e reverenciar a figura de Bom Jesus. Numa estreita articulação entre as dimensões do sagrado e do profano, muitos dos devotos se reuniam em alguns pontos da cidade para celebrar o evento por meio da formação de rodas de samba (CUNHA, 1937; ANDRADE; 1937; MANZATTI, 2006), como bem aponta o trecho da música Samba de Pirapora, de Geraldo Filme ${ }^{2}$ :

Eu era menino... / Mamãe disse "vâmo embora", / Você vai ser batizado / No samba de Pirapora // Mamãe fez uma promessa / Para me vestir de anjo / Me vestiu de azul celeste / Na cabeça um arranjo. / Ouviu-se a voz do festeiro / No meio da multidão, / Menino preto não sai / Aqui nessa procissão / Mamãe mulher decidida / Ao santo pediu perdão / Jogou minha asa fora, / Me levou pro barracão // Lá no barraco tudo era alegria / Negro batia na zabumba e o boi gemia //Iniciado o negrinho / Num batuque de terreiro, / Samba de Piracicaba, / Tietê e campineiro / Os bambas da Pauliceia / Não consigo me esquecer / Fredericão na zabumba / Fazia a terra tremer / Cresci na roda de bamba / No meio da alegria, / Eunice puxava o ponto, / Dona Olímpia respondia. / Sinhá entrava na roda / Gastando a sua sandália... / E a poeira levantava / No vento das sete saias // Lá no barraco tudo era alegria / Negro batia na zabumba e o boi gemia ${ }^{3}$

Conforme apresentado, os estudos recentes sobre o samba e o carnaval em São Paulo enfatizaram a alusão ao trânsito de participantes entre o samba batucado nas rodas de Pirapora do Bom Jesus e o samba realizado na cidade de São Paulo. Neste trabaIho, gostaria de contribuir para uma visão diversificada sobre o samba e o carnaval realizado no estado de São Paulo detendo-me sobre a apresentação das atuais manifestações do samba de bumbo durante os festejos do carnaval na cidade de Santana do Parnaíba, apontando para mais uma configuração particular entre samba e carnaval.

\section{NOTAS HISTÓRICAS SOBRE A CIDADE DE SANTANA DO PARNAÍBA E SUA “VOCAÇÃO" CULTURAL}

A cidade de Santana do Parnaíba está situada na região metropolitana de São Paulo, fazendo divisa com municípios próximos à capital, como Osasco, Barueri e Pirapora do Bom Jesus. Seu surgimento data da fundação da fazenda do casal Manoel Fernandes e Suzana Dias, em 1580, iniciando-se o povoamento do que viria a ser Santana do Parnaíba. Já em 1625, o local se destaca como vila colonial, devido sua posição privilegiada para que bandeiras e entradas se preparassem para adentrar o sertão, tendo o Rio Tietê como orientador e as rotas abertas pelos indígenas, que chegavam ao interior de Goiás, Mato Grosso e Minas Gerais.

A prosperidade dos empreendimentos bandeirantes tornou Santana do Parnaíba um polo de atração, em que muitos negócios e estabelecimentos surgiam em função do desbravamento dos sertões: o comércio, a oferta de tropas de burros para o transporte de cargas. A riqueza parnaibana atraía nobres e religiosos da então Capitania de São Paulo com suas grandes festas, como a homenagem a Nossa Senhora da Conceição, entre outras. 
Foi a descoberta do ouro na região central do Brasil pelos próprios bandeirantes que assinalou o período de estagnação que iria tomar Santana do Parnaíba. Primeiro a lavoura de cana-de-açúcar e, depois, a de café ensaiaram uma revitalização econômica durante o século XVIII. Porém, de modo geral, o povoamento parnaibano passou a se manter com suas roças de subsistência. As estradas de ferro, que atendiam à dinâmica da economia cafeeira, passaram ao largo de Santana do Parnaíba e foram atender Cajamar, Barueri, e Jundiaí.

Em 1901, chega a construção da primeira hidrelétrica do estado, logo ali no leito do Tietê, pela São Paulo Tramway, Light and Power, realizando o atendimento da capital em termos de consumo de energia elétrica. Em 1906, a antiga vila foi elevada à categoria de cidade. Porém, o surto industrial paulista se dirigiu à região sul, em direção ao Grande $A B C$ (os municípios de Santo André, São Bernardo e São Caetano).

A dinâmica industrial de São Paulo a partir dos anos 1940 e 1950 acabou por dominar toda a região de seu entorno. Grandes eixos rodoviários foram abertos para atender ao desenvolvimento industrial. Porém, Santana do Parnaíba não foi beneficiada diretamente com tais transformações, ficando localizada entre duas grandes rodovias: a Anhanguera e a Castelo Branco.

A partir da década de 1980, Santana do Parnaíba começa a receber grande quantidade de migrantes. $\mathrm{O}$ inchaço populacional do município pode ser acompanhado no seguinte quadro:

\begin{tabular}{|c|c|c|c|c|}
\hline \multicolumn{5}{|c|}{ População total de Santana do Parnaíba (no habitantes) } \\
\hline 1980 & 1990 & 1996 & 1998 & 2000 \\
\hline 10.057 & 37.762 & 57.299 & 61.560 & 74.828 \\
\hline Fonte: IBGE & \multicolumn{4}{|l}{} \\
\hline
\end{tabular}

O acesso à rodovia Castelo Branco não trouxe mudanças imediatas em Santana do Parnaíba, mas facilitou a procura por casas por parte de moradores de São Paulo, seja para veraneio ou para especulação imobiliária.

Foi nesse período que grandes incorporadoras imobiliárias implantaram enormes condomínios residenciais de alto padrão, inicialmente em Barueri e em seguida alastrando-se por parte do município de Santana de Parnaíba, tais condomínios são conhecidos como Alphaville e Tamboré. Atualmente, Barueri tornou-se um grande centro empresarial enquanto o bairro de Santana do Parnaíba no qual se alocam os condomínios é predominantemente residencial.

Esse rápido tour histórico sobre a localidade é relevante para compreender algumas linhas de desenvolvimento acompanhadas pela cidade. Se seu apogeu aconteceu em seus primórdios, durante a dinâmica bandeirista, no restante de sua história, Santana do Parnaíba nunca mais se beneficiou de nrnhum outro ciclo ou onda econômica no estado. A estagnação econômica vigente deu margem para que o "passado" de Santana do Parnaíba passasse a ser considerado patrimônio cultural e, tanto edificações e conjunto 
urbanístico do centro da cidade, quanto manifestações culturais populares passaram, ao longo do tempo, a ser um valor de orientação para o desenvolvimento econômico local.

É nesse movimento que se percebe a construção gradual da vocação "cultural" de Santana do Parnaíba. Assim, na década de 1940, a cidade teve três imóveis tombados pelo Instituto do Patrimônio Histórico e Artístico Nacional (Iphan): a Casa do Anhanguera e o Casarão, localizados no Largo da Matriz; e a Capela do Voturuna, abrigada numa fazenda no bairro rural de mesmo nome. Na década de 1970, a folclorista Haydée Nascimento (1977) consolidou a documentação das expressões vinculadas ao período carnavalesco. Em 1982, o Conselho de Defesa do Patrimônio Histórico, Arqueológico, Artístico e Turístico (Condephaat), órgão ligado à Secretaria de Estado da Cultura de São Paulo, realiza o tombamento do conjunto do centro histórico, incluindo imóveis como a Igreja Matriz, casas, sobrados, e espaços públicos como ruas, largos e praças.

Nessa dinâmica, o poder público local sempre apoiou a organização e a realização dos eventos e celebrações da cidade, que são muitos.

As festividades de carnaval e Corpus Christi se desenvolvem tendo o centro histórico de Santana do Parnaíba como referência. A marcha do primeiro e a procissão do segundo iniciam-se no Largo da Matriz, diante da Igreja de Nossa Senhora de Santana e percorrem as ruas e praças de feição colonial.

O carnaval de Santana de Parnaíba é composto da expressão de inúmeros grupos musicais, como blocos, escolas de sambas e bailes. Porém, o destaque fica para a apresentação dos grupos de samba de bumbo. O agrupamento Galo Carijó é o de maior relevo, abrindo as comemorações carnavalescas da cidade na noite de sexta-feira. Esta abertura oficial é chamada de Grito da Noite. Mais adiante este evento será melhor detalhado.

Além do cortejo do samba de bumbo, participam no Grito da Noite os chamados cabeções. Os cabeções são bonecos gigantes ou alegorias para serem encaixadas na cabeça, feitas de papier-maché. A brincadeira fica por conta das pessoas desfilarem pelas ruas da cidade com as figuras de caveiras e demônios ou de personalidades políticas, ao som do ritmo do samba de bumbo. (figuras 1 e 2)

Ao contrário da irreverência e do extravasamento dos dias carnavalescos, a festa religiosa de Corpus Christi preza pela solenidade. As ruas do Centro Histórico são cobertas por um longo tapete colorido, que parte da frente da Igreja Matriz e faz seu percurso até chegar às costas da mesma igreja, acompanhando o trajeto da procissão religiosa. O tapete é confeccionado na véspera do feriado pelos moradores da cidade, que passam a madrugada desenhando o chão com serragem colorida, cinzas e sementes. Os motivos artísticos podem variar, mas predominam os temas religiosos. Pelo envolvimento comunitário e pela beleza plástica, o tapete para celebração de Corpus Christi em Santana do Parnaíba merece atenção.

Enquanto o carnaval e o Corpus Christi povoam o centro histórico da cidade, em alguns bairros rurais que constituem o município de Santana de Parnaíba também ocor- 


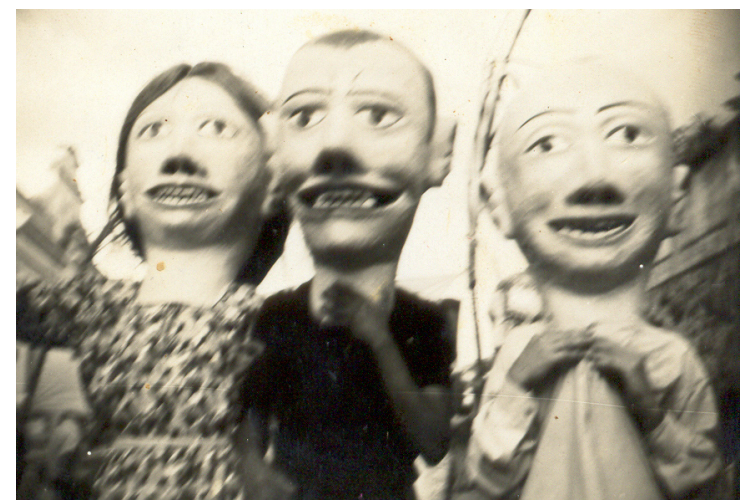

Figura 1: Cabeções.

Foto: Arquivo Prefeitura de Santana do Parnaíba, s/d.

rem eventos vinculados a construções particulares situadas nesses lugares afastados. É o caso da Festa do Cururuquara, que é realizada no dia 13 de maio, em comemoração à data da Abolição da Escravatura, no bairro de mesmo nome. A celebração tem como referência a Capela das Palmeiras, para a qual é encaminhada a imagem de São Benedito. Nesse dia é realizada uma missa na capela e uma congada faz sua reverência, por meio da realização do samba de bumbo, brincando no Largo da Capela.

Os festejos juninos também são de grande relevo nos bairros do município. Há a Romaria de Santo Antônio do Suru e a Festa de São João da Vila Nova. A romaria acontece na semana do dia 13 de junho, em homenagem ao santo citado. Homens montados em cavalos partem do centro histórico e cavalgam até a capela de Santo Antônio, localizada no bairro do Suru. É uma devoção conhecida desde o começo do século XX. Para animar a festa, o Grupo São Gonçalo faz suas apresentações. Já na semana de 24 de junho, é comemorada a Festa de São João da Vila Nova. Ali a referência é a Capela de São João, situada no bairro de Vila Nova. Nesse evento é realizada uma missa e a quermesse acontece ao redor da capela.

Como se viu até aqui, o samba de bumbo em Santana do Parnaíba é somente uma expressão dentre as mais variadas, associadas ao movimento de valorização do elemento cultural enquanto vetor de desenvolvimento econômico local. Passemos agora ao que interessa.

\section{APONTAMENTOS ETNOGRÁFICOS DE UMA NOITE DE CARNAVAL}

As observações aqui registradas fazem parte de uma visita realizada à municipalidade de Santana do Parnaíba no carnaval de fevereiro de 2007.

Como comentado anteriormente, o carnaval é formado por inúmeras formas de expressão como blocos, escolas de samba, os cabeções ${ }^{4}$, que se articulam e se revezam durante os dias da folia ${ }^{5}$. Porém, o grande destaque da comemoração é o momento de abertura oficial do Carnaval, que é realizado na sexta-feira e é chamado de Noite dos Fantasmas. 


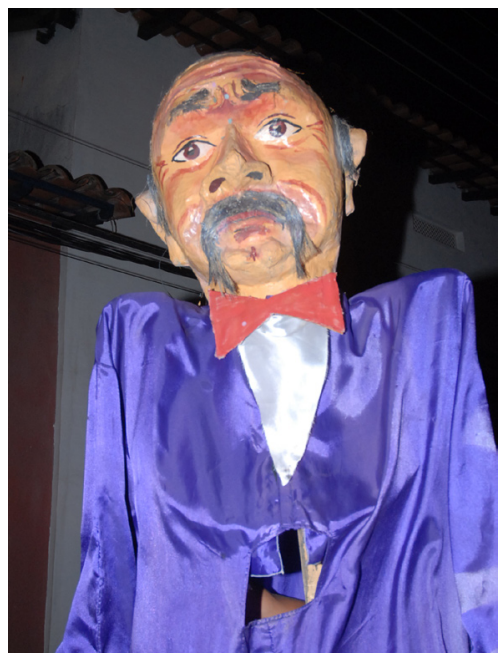

Figura 2: Cabeção. Foto: Sávio. Arquivo Secretaria Municipal de Comunicação de Santana de Parnaíba, 2007.

O nome Noite dos Fantasmas é uma referência carnavalesca ao evento de "encomendação das almas". Segundo relatos orais, em tempos antigos, era realizada na cidade, na data da Sexta-Feira Santa, uma procissão em reverência aos finados, que partia do cemitério local e percorria algumas ruas do centro. As pessoas trajavam mantos brancos, carregando velas e tochas, emanando rezas sacras. Registros bibliográficos também documentam o evento:

D. Arabela contou que na Procissão das Almas, os grupos seguiam [...] de camisolas brancas, também rezando, com matraca de Semana Santa, e se flagelavam para pagar os pecados que tinham cometido durantes o ano, então diz que era uma coisa medonha. Meu pai que morreu o ano passado, contava que ele quando menino, chegou, não a ver direito, porque tinha pavor, mas ouvia quando passava aquela ladainha, aquela gemedeira, não tinha mais a flagelação, mas ele disse eu tinha pavor daquilo, então ele entrava na cama, cobria a cabeça e ficava suando apavorado. Então, depois disso, o negócio foi modernizado, então se transformou em Carnaval hoje. O pessoal sai com esses lençóis enrolados, capuzes e com aquele samba. Então já virou brincadeira. [...]

$\mathrm{P}$ - A senhora sabe quem trouxe isso para o Carnaval?

$\mathrm{R}-\mathrm{Ah}$, isso não sei, porque desde criança que eu vejo isso, não sei quem transformou isso em Carnaval. (NASCIMENTO, 1977, p. 58-59)

Atualmente, a Noite dos Fantasmas conta com a presença de inúmeras figuras do "outro mundo", como fantasmas e esqueletos. Assim, foliões mais tradicionais se vestem com lençóis ou batas brancas, imitando fantasmas. E com a popularização do halloween norte-americano em terras brasileiras, há fantasiados de vampiros e bruxas. A Noite dos Fantasmas, conforme sua dita inspiração, também é um cortejo. $O$ préstito acontece através da apresentação do Grupo Galo Carijó, responsável pela execução do samba de bumbo em plena folia carnavalesca. 


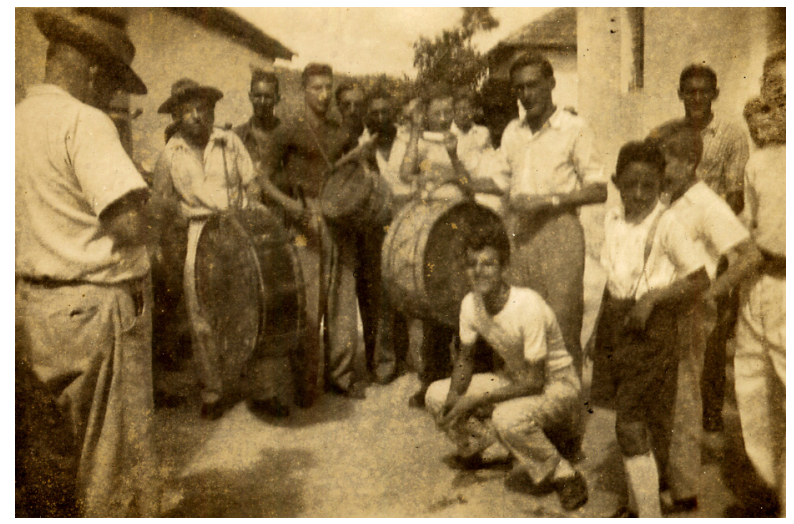

Figura 3: Grupo de samba de bumbo no carnaval de 1954. Foto: Arquivo Prefeitura de Santana do Parnaíba, 1954.

O chamado samba de bumbo é uma expressão musical tradicional dessa região paulista. (figura 3) Mário de Andrade registrou, em 1937, o samba de bumbo da cidade de Pirapora de Bom Jesus. Pirapora do Bom Jesus e Santana do Parnaíba, no passado, eram consideradas áreas de uma mesma parte administrativa. Mais tarde, foram separadas em municipalidades distintas. Não é possível precisar a origem exata do samba de bumbo, mas diz-se que está ligada à presença dos negros, trazidos como mão de obra escrava para as lavouras de cana-de-acúcar e café da região, e se transformou num brinquedo executado pelas classes mais humildes.

A história do samba de bumbo em Santana do Parnaíba está ligada à figura de Henrique Preto, que desempenhava profissões, como a de cozinheiro, e frequentava terreiros de umbanda da região. (NASCIMENTO, 1977) Segundo fontes municipais oficiais, Henrique Preto participava do grupo de samba de bumbo Galo Preto, mas devido a desentendimentos com outro integrante, Quirino Preto, resolveu criar seu próprio bloco, o Galo Carijó. Há histórias de encontros conflituosos entre os dois grupos, que, quando se encontravam, "voava até bumbo". Existe até a seguinte letra de samba, cantada até hoje: "Eu tenho pena / Eu tenho dó / Do Galo Preto / Apanhá do Carijó".

Apesar da rivalidade, os dois agrupamentos eram os responsáveis por muitos festejos na região. Os integrantes do Galo Preto foram falecendo no decorrer do tempo e permaneceram os integrantes do Galo Carijó. Em numerosos relatos orais, a idéia de realizar uma procissão na sexta-feira de carnaval, baseada na "procissão das almas", foi justamente de Henrique Preto, que, contam, teve um sonho a respeito.

Em linhas gerais, hoje em dia, a formação instrumental de um grupo de samba de bumbo, tanto em Santana do Parnaíba quanto em Pirapora do Bom Jesus, é composta de bumbo, caixa e chocalho, instrumentos que tocam um ritmo muito particular e acompanham o canto de uma letra coletiva. (figura 4) Cada grupo possui seu repertório de músicas, que muitas vezes fazem referências a coisas testemunhadas pelos seus integrantes. E cada conjunto é comandado por uma pessoa de notório conhecimento e vivência no mundo do samba de bumbo chamado de "dono do samba". É o "dono do samba" que 


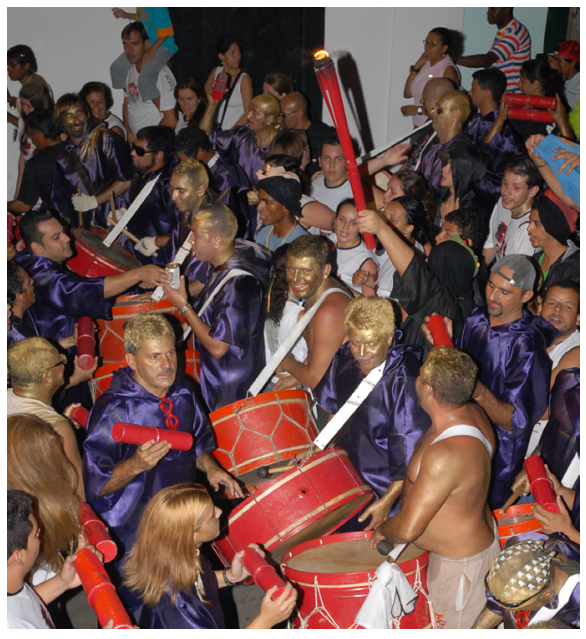

Figura 4: Grupo de samba de bumbo Galo Carijó tocando bumbos, caixas e chocalhos.

Foto: Sávio. Arquivo Secretaria Municipal de Comunicação de Santana de Parnaíba, 2007.

convoca os integrantes para brincar e que, durante a brincadeira, seleciona as músicas a serem executadas, conforme o calor da hora.

Se o samba de bumbo de Henrique Preto tem vivência na memória local desde a década de 1930, com sua morte, na década de 1970, o novo "dono de samba" passou a ser Nelson Moraes, empregado da Companhia Light e, por certo período, também vereador da cidade. Atualmente, o "dono do samba” do Grupo Galo Carijó é Daniel Daher, o Deco, empregado da Companhia Ambiental do Estado de São Paulo (Cetesb) e morador de um dos condomínios residenciais do município.

O samba de bumbo pode ser realizado a qualquer momento, bastando que seus integrantes se juntem para brincar. Porém, existem ocasiões especiais nas quais os grupos são presenças indispensáveis de animação.

Em Pirapora do Bom Jesus, o evento que coloca em destaque a presença do samba de bumbo é a Romaria ao Senhor Bom Jesus. Romeiros de toda a região visitam a cidade entre o final do mês de julho e o início de agosto. Historicamente, sempre foi nessa circunstância que inúmeros grupos de samba de bumbo se reuniam, compartilhavam os divertimentos e se desafiavam musicalmente. Aí, a formação básica da brincadeira é a de um samba de roda, em que os participantes se organizam num círculo: músicos e público fazendo a roda e dançadores no centro. Assim, a roda é o lugar de realização do samba de bumbo. Existem muitos testemunhos que manifestam a ligação entre o samba de bumbo e o samba realizado na cidade de São Paulo, pois muitos dos sambistas paulistanos frequentavam a Romaria ao Senhor Bom Jesus por meio dos grupos de samba de bumbo.

Já em Santana do Parnaíba, o festejo que sublinha a existência do samba de bumbo é o Ccarnaval. Aqui, o grupo tradicional Galo Carijó realiza a brincadeira numa formação que chamaremos no texto de "samba de cortejo", pois o agrupamento musical se desloca pelas ruas do centro histórico executando um desfile e marchando conforme 
o ritmo dos instrumentos de percussão. Interessante notar que tal deslocamento coloca duas fileiras de músicos uma de frente pra outra. Enquanto uma fileira marcha de frente, a outra, anda de costas. É como se o grupo desfilasse com a formação de uma roda de samba em movimento unidirecional, enquanto o público folião o segue ao redor.

Desse modo, enquanto em Pirapora do Bom Jesus o samba de bumbo é sublinhado pelo aspecto religioso da romaria, em Santana do Parnaíba ele enfatiza o aspecto lúdico e satírico do carnaval. Porém, tanto os elementos religiosos quanto os lúdicos estão presentes em ambas as manifestações, só que de maneiras diferentes. Por exemplo, enquanto o âmbito religioso é o mote do samba de bumbo de Santana do Parnaíba (a procissão de encomendação das almas a ser carnavalizada), em Pirapora do Bom Jesus o elemento religioso é o contexto (o evento da romaria). Já o aspecto lúdico, que é verborrágico no samba de bumbo carnavalesco de Santana do Parnaíba, em Pirapora do Bom Jesus é um contraponto à reverência e sobriedade da veneração religiosa.

Ao grupo musical Galo Carijó, também se junta a apresentação dos Cabeções, alegorias gigantes vestidas ou levadas por foliões junto do cortejo.

Como já explicitado, a "carnavalização" é o principal mecanismo acionado pelo samba de bumbo de Santana do Parnaíba. A partir daqui, vamos realizar a descrição do evento presenciado.

Na noite da sexta-feira do carnaval, a cidade de Santana do Parnaíba se prepara inteira para o início dos festejos. As instâncias do poder público tomam as devidas providências de segurança e enfeitam as ruas para o evento. Alguns foliões já perambulam pelas ruas caracterizados.

Para a noite, os integrantes do grupo Galo Carijó se preparam bebendo muita aguardente. Apesar do constrangimento para as autoridades locais, tal costume é imprescindível para o grupo. Por volta das 22 horas, eles se dirigem ao Casarão da Praça da Matriz, onde atualmente está instalada a Secretaria Municipal de Cultura e Turismo, e onde estão armazenados os instrumentos musicais. Numa sala dentro do próprio órgão municipal, o grupo de músicos inicia o aquecimento, fazendo tremer chão e paredes.

Quando saem à rua, uma multidão já os aguarda para o início dos festejos. Então, reiniciando ao ar livre as batidas compassadas dos bumbos, caixas e chocalhos, o "dono" do samba, que atualmente é o Sr. Deco, joga uma letra, que é instantaneamente ecoada por todos os brincantes.

Interessante notar que as letras dos sambas são criações do passado que se consolidaram como repertório do grupo. Letras antigas e de tempos imemoriais são novamente revividas durante o carnaval. Ao contrário dos sambas-enredos das escolas de samba, que devem ser criações inéditas - uma nova música a cada ano de apresentação -, o samba de bumbo reaviva músicas tradicionais, que já estão na cabeça dos foliões locais de outros carnavais. Letras como "O pau rolo / O pau caiu / Lá na mata ninguém viu" são cantadas em coro por toda a multidão juntamente com os integrantes do Grupo Galo Carijó, assim que são acionadas. 
Com o ritmo pontuado nos instrumentos e a letra na ponta das línguas, a marcha de foliões realiza seu percurso pelas ruas do centro histórico de Santana de Parnaíba. As variadas letras se sucedem, conforme o humor dos foliões e sob o comando do "dono" do samba. Em determinados pontos, a marcha é contida pelo oferecimento de bebida alcoólica de algum morador aos músicos. Das sacadas das janelas ou dos portões das casas, destilados ou fermentados são ofertados ao grupo. Então, os músicos agradecem cantando letras como, "Por esse litro tão querido / Obrigado meu amigo" ou "Carrero de paca / Carrero de lebre / Traiz a pinga / Que nóis bebe".

Às vezes, a folia estaciona em frente a algum estabelecimento e o grupo de músicos solicita ser presenteado com mais bebida. Se o proprietário não dá, é possível ser execrado publicamente com um: "A pinga que você negou / Agora não quero mais / Eu quero que esse buteco / Feche e nunca abra mais".

Assim, a folia carnavalesca do samba de bumbo atravessa a noite e atravessa a cidade. Durante o percurso, a exaltação vai crescendo cada vez mais, no toque do bumbo e na bagunça da multidão. Toda a excitação é finalizada numa espécie de apoteose, em que o grupo de foliões que saiu em cortejo se encontra com os foliões que aguardam na praça atrás da Igreja Matriz. A multidão se multiplica e nesse ponto final todos brincam a chegada do carnaval com o samba de bumbo do Galo Carijó.

\section{CONSIDERAÇÕES FINAIS}

A festa de Carnaval levada pelo samba de bumbo em Santana do Parnaíba é um evento cuja proporção permite que se acionem relações sociais e se brinque simbolicamente com muitos dos sentidos locais.

O carnaval local só pode ser totalmente vivenciado por frequentadores e moradores na medida que somente estes têm conhecimento do repertório de toadas a ser acionado. O cantar conjunto torna o cortejo, ao menos temporariamente, uma comunidade de sentido folião.

Com as limitadas informações que apresentamos, é possível sugerir que o cortejo levado pelas ruas do centro histórico da pequena cidade apresenta elementos da carnavalização bakhtiniana.

O carnaval é um espetáculo sem ribalta e sem divisão entre atores e espectadores. No carnaval todos são participantes ativos, todos participam da ação carnavalesca. Não se contempla e, em termos rigorosos, nem se representa o carnaval mas vive-se nele, e vive-se conforme as suas leis enquanto estas vigoram, ou seja, vive-se uma vida carnavalesca. Esta é uma vida desviada da sua ordem habitual, em certo sentido uma "vida às avessas", um "mundo invertido". (BAKHTIN, 1997, p. 122-123)

O primeiro indício parte da própria apropriação do evento da encomendação das Almas que é totalmente carnavalizado durante a folia. Um momento que deveria ser de resguardo, pesar e reverência pelos mortos é transformado em festa e júbilo. Os fantasmas e figuras do "outro mundo" comparecem para festejar junto aos vivos. O carna- 
val de Santana do Parnaíba parodia um acontecimento ligado ao período da quaresma. O carnaval enquanto celebração da abundância e do desregramento faz troça da morte e do período de comedimento e despojamento da quaresma que se segue.

Outro indício fica por conta da realização de interações sociais por meio da aguardente. Somente durante o carnaval é possível exigir o compartilhamento do estado de bebedeira. Por isso, durante a marcha do grupo de samba de bumbo, moradores e estabelecimentos comerciais são conclamados a compartilhar de bebidas alcoólicas junto à multidão de foliões. Quem se nega, recebe uma reprimenda satírica por parte do agrupamento carnavalesco.

Assim, por meio da inversão de sentidos, da profanação do sagrado e da celebração do grotesco por meio da bebida, o carnaval de Santana do Parnaíba se manifesta. Ao mesmo tempo, conforme Bakhtin (1997) já apontava, tal celebração tem o potencial de questionar hierarquias e realizar reflexões ou críticas à sociedade local. Há algum tempo atrás, nem religiosos escapavam:

\section{$\mathrm{P}-\mathrm{E}$ aquela história do padre?}

Pois é, então eles sempre tinham uma oportunidade pra provocação, como chegar embaixo da janela do padre cantar, e sambar:

A ceroula do padre caiu no chão

Segura ceroula seu porcalhão. (NASCIMENTO, 1977)

A folia carnavalesca de Santana do Parnaíba coloca em interação cerca de 15 mil pessoas nas ruas da cidade, segundo levantamentos da prefeitura.

Desse modo, pretendeu-se aqui oferecer subsídios para se pensar o carnaval e o samba em São Paulo enquanto um universo diverso, no qual cabem expressões particulares da região, ressaltando, assim, que existem carnavais e sambas de vigor e de estilos diferenciados no estado de São Paulo e que nem tudo é "cópia" de modelo carioca ou nordestino.

Além disso, sublinha-se aqui que o carnaval e o samba de bumbo em São Paulo não se ligam somente pela memória, como no caso das escolas de samba paulistanas. Tentou-se ressaltar que, para a localidade de Santana do Parnaíba, samba de bumbo e carnaval são elementos de uma mesma folia atual. ${ }^{6}$

\section{NOTAS}

1 Alguns autores caracterizam o samba como de bumbo, pois este instrumento é o centro da rítmica desses eventos. São recorrentes também caixas e chocalho, caracterizando tais instrumentos como conjunto básico das brincadeiras.

2 Geraldo Filme nasceu por volta de 1930 e morreu em 1995, foi fundador do Cordão Paulistano da Glória, participava dos carnavais do Bexiga e transitou por inúmeros redutos negros paulistanos como a Barra Funda, na Zona Norte, participando também dos encontros de bamba do Largo da Banana, da Praça do Correio e do Largo da Sé.

3 Extraído do CD "História do Samba Paulista", narrada e cantada por Oswaldinho da Cuíca , participação de Aldo Bueno, Germano Matias e Tobias da Vai-Vai, Gravadora CDC UMES, distribuído pela Eldorado Fonográfica, 1999. 
4 Para uma aproximação mais acurada de uma experiência em campo, ver Nascimento (1977).

5 Em 2009, a programação de carnaval contava: Sexta 23h00 Abertura oficial do carnaval - Noite dos Fantasmas - grupo folclórico Grito da Noite / sábado 15 h00 bloco Galo do Meio Dia / $18 \mathrm{~h} 00$ bloco Bar-to-beleza / $20 \mathrm{~h} 00$ bloco Berro da Noite do Sexo Forte / domingo $13 \mathrm{~h} 30$ bloco Mocidade do São Luís / 15h30 bloco Os Picaretas / 19h00 desfile das escolas de samba / segunda 14 h00 bloco do Ibraim / 17 h00 bloco Alegria dos Koroa / $19 \mathrm{~h} 00$ bloco Nossa Cara / terça $14 \mathrm{~h} 00$ bloco Praieiros / $18 \mathrm{~h} 00$ desfile das escolas de samba.

6 Agradeço à Prefeitura de Santana de Parnaíba pela oportunidade de acompanhar o carnaval de 2007 e pela disponibilização de materiais e imagens sobre o evento, alguns deles utilizados neste texto.

\section{REFERÊNCIAS BIBLIOGRÁFICAS}

ANDRADE, Mário. Samba rural paulista. São Paulo: Departamento de Cultura, 1937.

BAKHTIN, M. A cultura popular na Idade Média e no Renascimento: o contexto de François Rabelais. São Paulo: Hucitec/ UnB 1997.

CUNHA, Mário Wagner Vieira da. Festa de Bom Jesus de Pirapora. São Paulo: Departamento de Cultura, 1937.

MANZATTI, Marcelo. Samba paulista, do centro cafeeiro à periferia do centro: estudo sobre o samba de bumbo ou samba rural paulista. São Paulo: Pontifícia Universidade Católica de São Paulo, Dissertação de Mestrado, 2006.

NASCIMENTO, Haydée. Aspectos folclóricos do carnaval de Santana do Parnaíba. São Paulo: Conselho Estadual de Artes e Ciências Humanas, 1977.

VON SIMSON, Olga R. de Moraes. Carnaval em Branco e Negro: carnaval popular paulistano (1914-1988). Campinas: Ed. da Unicamp, EDUSP e Imprensa Oficial, 2007.

Simone Toji é Mestre em Antropologia e Sociologia pelo IFCS/UFRJ. 
